\title{
The effect of beet fibers on the properties of elk meat semi-finished products
}

\author{
Inessa Zachesova ${ }^{1}$, Stanislav Kolobov ${ }^{2,3,{ }^{*}}$, and Natalia Shagaeva ${ }^{1}$ \\ ${ }^{1}$ Moscow State Academy of Veterinary Medicine and Biotechnology - MVA named after K.I. \\ Skryabin, Russia \\ ${ }^{2}$ Plekhanov Russian University of Economics, Russia \\ ${ }^{3}$ Russian Presidential Academy of National Economy and Public Administration, Russia
}

\begin{abstract}
When developing the technology of meat products with dietary fiber, the question arises of the need to obtain optimal consistent and organoleptic characteristics, that is, specific values of the structuralmechanical, functional-technological parameters of these products, objectively reflecting the consistency. This article is devoted to the results of a study of organoleptic quality indicators, functional-technological and structural-mechanical properties of chopped semi-finished products (cutlets) from elk meat with the addition of beet fibers (fiber). As the material for the study, we used samples of chopped semi-finished products without and with the addition of beet fibers (fiber) instead of bread in the amount of $25 \%, 50 \%, 75 \%, 100 \%$. In the process of work, generally accepted methods of researching the organoleptic, functional-technological and structural-mechanical properties of meat products were used. Studies have led to the conclusion that the properties studied depend on the amount of fiber added and the higher its content, the higher the yield of the product, but lower sensory and strength indicators of quality. Replacing $50 \%$ of bread with beet fibers is optimal from the point of view of forming the consistency and taste of the product, and also contributes to its enrichment with dietary fiber.
\end{abstract}

\section{Introduction}

Due to the consumption of foods containing a large amount of fats and simple carbohydrates, as well as due to a lack of fruits and vegetables, the diet of the majority of the population does not comply with the principles of healthy eating $[1,2]$.

In most cases, food manufacturers do not think about consumers' health, and in order to reduce the cost of finished products, they often replace expensive ingredients with substitutes or additives that do not make the products of high quality [3].

However, it should be noted that the world market for health and wellness products is growing steadily.

The increase in the turnover of the market for healthy food products is a direct consequence of the changes in the model of consumer consumption, and the criteria for consumers to choose healthy products in the market are not only price, taste and quality, but

\footnotetext{
* Corresponding author: 97rus@mail.ru
} 
also such a new group of criteria as health and healthy lifestyle, product safety . Consumers are increasingly interested in what exactly they consume, and what effect this has on their body $[4,5,6]$.

The presence of functional components makes it possible to increase the nutritional and biological value of the product, but various factors affect the decision of the manufacturer whether to use a specific functional ingredient or not: the level of food consumption, the biological effect of human exposure, stability in the food matrix and its effect on such quality parameters, like color, taste and texture $[7,8]$.

As functional ingredients that can improve the nutritional, functional and technological properties of a product, dietary fiber (fiber) is often used as by-products obtained from the production or processing of plant foods. The introduction of dietary fiber into a product as a functional ingredient is advisable in physiologically significant amounts compared with the daily norm (in the Hygienic Requirements for the Safety and Nutritional Value of Food Products, approved by the Ministry of Health of Russia in 2001, the calculated physiological need for dietary fiber is determined at $30 \mathrm{~g} /$ day with an energy value of the diet of $2500 \mathrm{kcal}$. In the methodological recommendations of the State Research Institute of Nutrition of the Russian Academy of Medical Sciences from 2008, the physiological need for dietary fiber for an adult is determined at $20 \mathrm{~g} /$ day The American Dietetic Association recommends the amount of dietary fiber $25-30 \mathrm{~g} /$ day. , the accepted norm is the intake of 25-35 g / day with the food eaten), and their use as a food additive requires the minimum amounts necessary to achieve specific technological goals. The main challenge facing technologists developing new products with dietary fiber is balancing between meeting the human body's needs for dietary fiber as a functional ingredient and maintaining the traditional quality of the fortified product [9-11].

Currently, the meat industry most often uses wheat and pea fiber, considering them more affordable among other types of fiber. However, these fibers contain phytic acid, which forms strong chemical complexes with iron and zinc, worsening or decreasing the natural absorption of these essential minerals in the human body. Wheat fiber contains gluten, which can cause an allergic reaction in people suffering from celiac disease (celiac enteropathy). Wheat dietary fiber is devoid of pectin, which stabilizes redox processes, lowers blood cholesterol, improves peripheral blood circulation, and also has a high moisture-binding, complexing and gelling ability (these technological properties are very important in the production of processed meat products). Beet fibers, on the other hand, are devoid of these components that negatively affect the human body and are rich in pectin [12-16].

Due to the negative attitude of the consumer to soybean in general, soybean fibers are less commonly used, despite the fact that they have good moisture-binding and emulsifying ability.

Cheap bamboo fibers are also not in demand, due to the fact that they have wide capillaries that slowly absorb water and quickly give it away under mechanical stress [17].

Buckwheat fiber has a dark gray color, a pronounced taste and smell of buckwheat, therefore it is recommended to introduce it into the recipe in combination with herbal additives, such as beet processing products (puree, infrared drying powders), which have high organoleptic characteristics (bright burgundy color, neutral taste), contain a significant amount of biologically active substances: betanin, betaine, vitamins B1, B2, PP, C and organic acids.

Dietary fibers of sugar beet pulp, grapevine, galley are able to bind $8 \mathrm{~g}$ of water per $1 \mathrm{~g}$ of fiber and therefore they are classified as strongly binding water.

Dietary fibers from wheat bran, alfalfa, grape pomace are able to bind $2-8 \mathrm{~g}$ of water per $1 \mathrm{~g}$ of fiber, they are referred to as medium binding water. 
And fibers from grape seeds and grain cake are considered to be weakly binding to water; they bind less than $2 \mathrm{~g}$ of water per $1 \mathrm{~g}$ of fibers [18].

"The material of the cell wall of sugar beet, due to its function in the plant, differs in characteristics from the fibers of cereal bran. The task of the cells in the bran is to protect the seeds, they are hard and lignified. The cell walls in sugar beets are primarily intended for storing nutrient reserves and are equally not lignified. These differences in cell structure give sugar beet fiber not only a unique fiber composition with $1 / 3$ soluble and $2 / 3$ insoluble fibers, but also interesting physical properties such as heat-resistant water retention. "

The high content of dietary fiber (a general term that characterizes carbohydrate components (non-starch polysaccharides) that are not digested or absorbed in the small intestine, but pass into the large intestine with little or no change) in sugar beet fiber, combined with water absorption, results in low energy density. thereby reducing the energy content of food.

In the meat industry, in order to save meat raw materials, to give a marketable appearance, it has become popular to use fiber, replacing part of the main raw material with it, however, from the point of view of nutritional and biological value, the introduction of fiber into meat products entails a decrease in the content of the most valuable nutrient in the meat product - complete protein. as well as fat. A decrease in the fat content in a semifinished meat product, for example, made from elk meat, which is already characterized by its low content, can adversely affect the consumer properties of the product.

In this regard, in our experimental minced meat semi-finished product made from elk meat, we propose to replace wheat bread with beet fiber, which in the cutlet mass serves as a moisture-absorbing material, imparting porosity to finished products, providing them with juiciness, but serving as a source of simple carbohydrates.

The purpose of the study was to establish the effect of beet fibers on the organoleptic, functional-technological and structural-mechanical properties of chopped semi-finished products (cutlets) from elk meat.

\section{Materials and Methods}

The material for the study was beet fibers and samples of chopped semi-finished products moose cutlets. Cutlets were made using cutlet of moose, baked veal pork, raw pork fat, fresh onion, chicken eggs, wheat bread, beetroot, black pepper.

Beet fiber was added instead of wheat bread in the amount of $0 \%$ (control), $25 \%$ (sample 1), 50\% (sample 2), 75\% (sample 3) and 100\% (sample 4).

After mixing the components, round-flattened patties were formed with a height of 1.5$2 \mathrm{~cm}$ and a weight of not more than $100 \mathrm{~g}$.

During the research, the total chemical composition of beet fibers (mass fraction of moisture, protein, fat, ash) was determined, organoleptic quality indicators, functionaltechnological (water-binding capacity (WBC), water-holding capacity (WHC), fat-holding ability (FHA), hydrogen index $(\mathrm{pH})$, yield) and structural-mechanical properties (penetration depth, cutoff stress, were determined at the inlet of the study). , cutting work) semi-finished products.

The mass fraction of moisture was determined by drying the samples at a temperature of $100-105^{\circ} \mathrm{C}$. Mass fraction of protein by the Kjeldahl method. Mass fraction of fat on the Soxhlet fat analyzer. Mass fraction of ash by calcining the mineral residue obtained by burning the sample.

Organoleptic quality assessment was carried out on a nine-point scale in accordance with GOST 9959-2015 "Meat and meat products. General conditions for organoleptic assessment" after heat treatment (frying); WBC was determined by the centrifugation method based on the separation of the liquid phase under the action of centrifugal force 
from the object under study and pressing, based on the removal of moisture from the sample under the action of pressure applied to it; WHC was determined by the difference between the mass moisture content in the sample and the amount of moisture separated during the heat treatment; FHA was determined by the difference between the mass content of fat in the sample and the amount of fat separated during the heat treatment.; active acidity $(\mathrm{pH})$ was determined in an aqueous extract using a $\mathrm{pH}$ meter-millivoltmeter; the yield was determined by weighing before and after heat treatment; the penetration depth was determined on an automatic penetrometer, the ultimate shear stress and the cutting work were determined according to the built-in schedule of the testing machine.

Since minced semi-finished products refer to emulsified meat products made from coarsely ground raw materials, with a partially preserved morphological structure of meat, a low degree of fat dispersion. The structure of such a product can be characterized by some looseness and the presence of air voids, intensifying oxidative damage inside the product under the influence of atmospheric oxygen. Therefore, it was decided to analyze the microbiological safety of the resulting semi-finished product.

Microbiological studies were carried out in accordance with GOST R 51447-99 «Meat and meat products. Sampling methods», GOST 10444.15-94 «Food products. Methods for determining the amount of mesophilic aerobic and facultative anaerobic microorganisms», GOST 31747-2012 «Food products. Methods for detecting and determining the number of bacteria of the group of Escherichia coli (coliform bacteria)», GOST 10444.12-2013 «Microbiology of food and animal feed», GOST 30726-2001 «Food products. Methods for detecting and determining the number of bacteria of the species Escherichia coli», GOST 31746-2012 «Food products. Methods for detecting and determining the number of coagulase-positive staphylococci and Staphylococcus aureus», GOST R 51921-2002 «Food products. Methods for the detection and determination of bacteria Listeria monocytogenes».

The experimental data obtained as a result of the studies were subjected to statistical processing using the Microsoft excel 2016 software package. The repetition of experiments (n) in the experimental studies was at least 3 times with 3-4 times the repetition of the tests.

\section{Results}

A sample of beet fiber was a homogeneous finely ground free-flowing powder of light cream color with a neutral taste, with an odor characteristic of dried fibers purified from beet odor, without foreign odor, impurities and pests with the following chemical composition (table 1).

Table 1. Chemical composition of beet fiber.

\begin{tabular}{|l|c|c|}
\hline № s $/ \mathrm{n}$ & name of indicator & mass fraction, $\%$ \\
\hline 1. & water & $7.28 \pm 0.23$ \\
\hline 2. & protein & $8.32 \pm 0.12$ \\
\hline 3. & fat & $1.05 \pm 0.07$ \\
\hline 4. & ash & $5.63 \pm 0.15$ \\
\hline 5. & carbohydrates & $7.52 \pm 0.15$ \\
\hline 6. & cellulose & $21.10 \pm 1.20$ \\
\hline 7. & hemicellulose & $25.42 \pm 1.37$ \\
\hline 8. & lignin & $3.05 \pm 0.21$ \\
\hline 9. & pectin & $20.63 \pm 0.15$ \\
\hline 10. & total dietary fiber & 70.20 \\
\hline
\end{tabular}

In its composition, beet fiber had a complex set of dietary fiber with dominant cellulose, pectin and hemicellulose made up approximately one third of the total amount of dietary 
fiber. Water-soluble PV (hemicellulose, pectin) accounted for $59.4 \%$ and insoluble PV (cellulose, lignin) $40.6 \%$.

The mass composition of the components did not exceed the established requirements of regulatory documents. The protein and ash in the composition will further increase the nutritional value of semi-finished products made from elk meat, the low fat content will not have a significant effect on the energy value of the product.

One of the important indicators of meat products subjected to heat treatment is the water-holding capacity of the raw material. This indicator characterizes the ability of raw materials to retain moisture during heating, which primarily affects the yield of the finished product. The obtained results of the study of the functional and technological properties of beet fibers (table 2) allow us to say that the object under study had high indicators of waterbinding, water-holding and fat-holding capacity, which in the future can have a positive effect on the functional and technological properties and the percentage of the produced semi-finished product.

Table 2. Functional and technological properties of beet fibers.

\begin{tabular}{|c|c|c|}
\hline № s/n & name of indicator & indicator value \\
\hline 1. & water-binding capacity, $\%$ & $69.32 \pm 0.65$ \\
\hline 2. & water-holding capacity, $\%$ & $88.56 \pm 0.32$ \\
\hline 3. & fat-holding capacity, $\%$ & $75.98 \pm 0.69$ \\
\hline
\end{tabular}

Knowledge of the water-holding capacity of dietary fiber allows you to increase the water-holding capacity of the product itself, which allows you to preserve its presentation for a long time, which is so important when selling.

The results of the organoleptic assessment of the quality of the cutlets showed that all the samples had a very beautiful, magnificent appearance, sample 4 was just beautiful with a more flattened, somewhat uneven shape.

All cutlet samples had an outwardly pleasant, intrinsic cut color for the heat-treated product, and were rated as very beautiful.

Control samples 1 and 2 had a pleasant, delicate, specific, non-distracting taste and aroma characteristic of elk meat. In samples 3 and 4, the appearance of an odor and taste unusual for meat cutlets was observed.

Sample 2 had the best, very delicate consistency; the control sample was less tender in relation to others. Adding $25 \%$ fiber did not have a significant effect on consistency. The addition of $75 \%$ and $100 \%$ caused excessive friability of the structure.

The juiciness of cutlets with a fiber content of less than 50\% was noted simply as juicy, in samples with more than $50 \%$ juiciness turned into watery. Sample 2 had the most acceptable juiciness -8.5 points.

Table 3. Organoleptic quality assessment of chopped semi-finished products (cutlets) from elk meat, points.

\begin{tabular}{|c|c|c|c|c|c|}
\hline \multirow{2}{*}{$\begin{array}{c}\text { name of } \\
\text { indicator }\end{array}$} & \multicolumn{5}{|c|}{ sample } \\
\cline { 2 - 6 } & controle & 1 & 2 & 3 & 4 \\
\hline appearance & $8.6 \pm 0.1$ & $8.6 \pm 0.1$ & $8.6 \pm 0.1$ & $8.5 \pm 0.1$ & $8.3 \pm 0.1$ \\
\hline cutaway color & $8.5 \pm 0.2$ & $8.5 \pm 0.1$ & $8.5 \pm 0.1$ & $8.5 \pm 0.1$ & $8.4 \pm 0.1$ \\
\hline flavor & $8.4 \pm 0.2$ & $8.4 \pm 0.1$ & $8.4 \pm 0.1$ & $8.3 \pm 0.1$ & $8.3 \pm 0.1$ \\
\hline teste & $8.5 \pm 0.1$ & $8.5 \pm 0.1$ & $8.5 \pm 0.1$ & $8.0 \pm 0.2$ & $7.8 \pm 0.1$ \\
\hline consistence & $8.4 \pm 0.1$ & $8.4 \pm 0.1$ & $9.0 \pm 0.1$ & $8.4 \pm 0.1$ & $8.2 \pm 0.2$ \\
\hline succulence & $8.3 \pm 0.1$ & $8.4 \pm 0.1$ & $8.5 \pm 0.1$ & $8.3 \pm 0.1$ & $8.3 \pm 0.1$ \\
\hline overall score & $8.5 \pm 0.2$ & $8.5 \pm 0.1$ & $8.6 \pm 0.1$ & $8.3 \pm 0.1$ & $8.2 \pm 0.1$ \\
\hline
\end{tabular}

As a result of the study, the results were obtained: control, 1, 2 samples received an overall quality rating - very good, samples 3 and 4 - good quality. 
The results of the study of the functional and technological properties of the control and prototypes are presented in table 4.

Table 4. Functional and technological properties of chopped elk meat semi-finished products.

\begin{tabular}{|c|c|c|c|c|c|}
\hline \multirow{2}{*}{ sample } & \multicolumn{5}{|c|}{ name of indicator } \\
\cline { 2 - 6 } & WBC, \% & WHC, \% & FHA, \% & pH & Output, \% \\
\hline controle & $68.52 \pm 0.17$ & $63.92 \pm 0.36$ & $68.17 \pm 0.51$ & $6.28 \pm 0.03$ & $76.77 \pm 0.32$ \\
\hline 1 & $75.21 \pm 0.32$ & $66.58 \pm 0.36$ & $70.28 \pm 0.48$ & $6.40 \pm 0.01$ & $79.64 \pm 0.42$ \\
\hline 2 & $80.29 \pm 0.20$ & $69.15 \pm 0.17$ & $72.64 \pm 0.40$ & $6.51 \pm 0.01$ & $82.56 \pm 0.32$ \\
\hline 3 & $83.92 \pm 0.20$ & $70.78 \pm 0.42$ & $76.15 \pm 0.42$ & $6.60 \pm 0.03$ & $85.06 \pm 0.42$ \\
\hline 4 & $84.12 \pm 0.43$ & $72.23 \pm 0.36$ & $79.02 \pm 0.36$ & $6.68 \pm 0.03$ & $87.62 \pm 0.51$ \\
\hline
\end{tabular}

The increase in the studied parameters of semi-finished products was characteristic of all samples, but to a different extent, which is explained by the use of different amounts of beet fiber.

An increase in the moisture-binding and water-holding capacity of all prototypes occurs due to an increase in the mass fraction of high-molecular proteins and polysaccharides, capable of swelling, accompanied by binding and retention of moisture.

The highest WBC was noted in sample No. 4, due to the high content of fiber, and therefore hemicellulose, which, according to the literature, has the highest coefficient of water-binding capacity among water-soluble dietary fibers. Thus, the WBC of sample 1 by $9.8 \%$, sample 2 by $17.2 \%$, sample 3 by $22.5 \%$, sample 4 by $22.8 \%$ more than the control. In samples 3 and 4, no difference was observed in the moisture binding capacity, which can be associated with a decrease in the concentration of hydrogen ions.

The WHC of sample 1 is $4.2 \%$, sample 2 is $8.2 \%$, sample 3 is $10.7 \%$, and sample 4 is $13.0 \%$ more than the control. The increase in the VUS of semi-finished products proves the role of beet fiber in the stabilization of meat coagulation structures.

FHA of sample 1 by $3.1 \%$, sample 2 by $6.6 \%$, sample 3 by $11.7 \%$, sample 4 by $16.4 \%$ more than the control.

An increasing hydrogen index confirms the results obtained on the juiciness of the product and increased yield.

Heat treatment losses are in direct proportion to the $\mathrm{WHC}$ and decreased in relation to the control. The product yield increased in test samples 1 to 4 by $3.7 \%, 7.5 \%, 10.8 \%$, $14.1 \%$, respectively, to the control sample.

To determine the strength and tenderness of the structure of the investigated semifinished product, structural and mechanical indicators were studied (table 5), since they, along with physicochemical, functional and technological indicators, play an important role in assessing the quality of a food product.

Table 5. Structural and mechanical properties of chopped elk meat semi-finished products.

\begin{tabular}{|c|c|c|c|}
\hline \multirow{2}{*}{ sample } & \multicolumn{3}{|c|}{ name of indicator } \\
\cline { 2 - 4 } & $\begin{array}{c}\text { penetration } \\
\text { depth, m x 10 }\end{array}$ & $\begin{array}{c}\text { shear stress } \\
\text { limit, } \mathrm{kPa}\end{array}$ & $\begin{array}{c}\text { cutting work, } \\
\mathrm{J} / \mathrm{m}^{2}\end{array}$ \\
\hline controle & $60.35 \pm 0.26$ & $73.90 \pm 0.44$ & $496.87 \pm 1.15$ \\
\hline 1 & $62.15 \pm 0.17$ & $73.05 \pm 0.36$ & $487.20 \pm 1.27$ \\
\hline 2 & $62.78 \pm 0.20$ & $72.67 \pm 0.25$ & $468.61 \pm 1.25$ \\
\hline 3 & $65.43 \pm 0.20$ & $71.95 \pm 0.32$ & $439.82 \pm 1.17$ \\
\hline 4 & $68.09 \pm 0.32$ & $70.66 \pm 0.42$ & $402.58 \pm 1.96$ \\
\hline
\end{tabular}

The control sample had the minimum value of the penetration depth and the maximum value of the limiting shear stress, which is consistent with the results of the organoleptic assessment, according to which this sample was characterized as the hardest. 
The depth of penetration increased with respect to the control. In the samples, the increase was in order of $3.0 \%, 4.0 \%, 8.4 \%, 12.8 \%$, respectively.

An organoleptic quality assessment showed that with an increase in beet fiber, an increase in the friability and water content of the structure is observed, which was accordingly confirmed by the results of the study of the ultimate shear stress and cutting work, these indicators decreased.

The ultimate shear stress decreased in 2 samples by $1.7 \%$, sample 3 by $2.6 \%$, sample 4 by $4.4 \%$ with respect to the control. Sample 1 showed a slight decrease and was within the error range.

The cutting work decreased in relation to the control. In the samples, the decrease was $1.9 \%, 5.7 \%, 11.5 \%, 19.0 \%$, respectively.

To establish the quality of the resulting semi-finished product, microbiological control was subjected to sample№ 2 with $50 \%$ beet fiber instead of bread, since it is known from the above that it had the best organoleptic quality indicators (table 6).

Microbiological parameters of the beet fiber sample met the requirements of TU 10.81.20-001-17021101-2017. The number of mesophilic aerobic and facultative-anaerobic microorganisms (NMAFAnM) was $1,3 \times 10^{1} \mathrm{CFU} / \mathrm{g}$, bacteria of the Escherichia coli group (BGCP) and mold were not detected.

Table 6. Microbiological safety indicators of minced semi-finished products from elk meat.

\begin{tabular}{|c|c|c|c|c|}
\hline \multirow{2}{*}{$\begin{array}{l}\text { № } \\
\mathrm{s} / \mathrm{n}\end{array}$} & \multirow[b]{2}{*}{ name of indicator } & \multirow{2}{*}{$\begin{array}{c}\text { norm } \\
\text { TR CU } \\
034 / 2013 \\
\end{array}$} & \multicolumn{2}{|c|}{ sample } \\
\hline & & & controle & sample №2 \\
\hline 1. & $\begin{array}{l}\text { Number of mesophilic aerobic } \\
\text { facultative anaerobic } \\
\text { microorganisms }\end{array}$ & $\begin{array}{c}\text { no more than } 5 \mathrm{x} \\
10^{6} \mathrm{CFU} / \mathrm{g}\end{array}$ & $3,9 \times 10^{3}$ & $3,6 \times 10^{3}$ \\
\hline 2. & E.coli group bacteria & $\begin{array}{l}\text { not allowed in } \\
0.0001 \mathrm{~g} \text { of } \\
\text { product }\end{array}$ & \multicolumn{2}{|c|}{ not detected } \\
\hline 3. & $\begin{array}{l}\text { Pathogenic microorganisms, } \\
\text { incl. salmonella and L. } \\
\text { monocytogenes }\end{array}$ & $\begin{array}{l}\text { not allowed in } \\
25.0 \mathrm{~g} \text { of product }\end{array}$ & \multicolumn{2}{|c|}{ not detected } \\
\hline 4. & E.coli & $\begin{array}{l}\text { not allowed in } \\
1.0 \mathrm{~g} \text { of product }\end{array}$ & \multicolumn{2}{|c|}{ not detected } \\
\hline 5. & S.aureus & $\begin{array}{l}\text { not allowed in } \\
0.1 \mathrm{~g} \text { of product }\end{array}$ & \multicolumn{2}{|c|}{ not detected } \\
\hline 6. & Molds & $\begin{array}{c}\text { no more than } \\
500 \mathrm{CFU} / \mathrm{g}\end{array}$ & \multicolumn{2}{|c|}{ not detected } \\
\hline
\end{tabular}

Analysis of the obtained data indicates a high quality of the semi-finished product, pathogenic microflora was not detected in the studied samples. Microbiological indicators did not exceed the regulatory indicators.

\section{Discussion}

The analysis of organoleptic quality indicators showed a difference in scores for such indicators as: smell, taste, texture, juiciness, which confirms the significance of the percentage of plant fiber in the composition of the product. The high fiber content can cause a foreign taste and smell, which is unacceptable in the production of chopped semifinished products.

Increasing indicators of water-binding, water-holding and fat-holding ability in experimental samples indicate high functional and technological properties of beet fibers, which are able to absorb moisture, increase in size during heat treatment, contributing to the 
retention of fat and water in the porous structure of the fibers. However, with the addition of more than $50 \%$ fiber, a decrease in the rates of BCC and CCC was observed; for HCL, such a decrease was noted with the addition of more than $75 \%$ fiber. Adding more than $50 \%$ fiber is also undesirable due to changes in organoleptic characteristics.

The results of the study of the structural and mechanical properties of sample 1 showed that the content of $25 \%$ of the fibers does not significantly affect the structure of the semifinished product.

The decrease in these indicators in samples 3 and 4 leads to the manifestation of minced meat antitixotropic properties, which is also confirmed by the results of organoleptic evaluation.

Adding fiber to the recipe reduces the weight loss of the product during heat treatment by an average of $9.1 \%$.

It should be noted a lower NMAFAnM in the developed sample No. 2 compared with the control, it can be assumed that this is due to weakly alkaline environment of the fiber, which does not allow the development of secondary microflora in the product. In addition, during the production process, fiber is subjected to heat treatment on all sides, and therefore, it is actually a free product from microorganisms, which can not be said about wheat bread, instead of which fiber was added. For example, the surface of bread when leaving the oven is almost sterile, but the crumb warms up only to $93-98{ }^{\circ} \mathrm{C}$, and it always retains a certain amount of bacterial spores; it is possible to preserve vegetative cells (when adding bread to the mince, the crust of bread is cut off).

\section{Conclusions}

An organoleptic assessment of the quality indicators of chopped semi-finished products from elk meat revealed that, with an increase in the content of beet fiber, a decrease in the intensity of aroma, the appearance of a peculiar aftertaste, excessive friability, wateriness, and a decrease in the fluffiness of the product were observed. The highest total score - 8.6 was gained by sample 2 (with $50 \%$ of the mass of bread), which had a very beautiful appearance, delicate and juicy texture, pleasant specific taste and aroma peculiar only to elk meat.

It was shown in the work that this sample was able to maintain the amount of moisture and fat specified by the recipe during preparation by an average of $69 \%$ and $72 \%$, respectively. The yield of the product was $82.56 \%$.

The penetration depth of sample 2 increased by $4.0 \%$, the ultimate shear stress and cutting work decreased by $1.7 \%$ and $5.7 \%$, respectively, relative to the control sample, which is consistent with the results of organoleptic evaluation.

The presence of fiber in the composition of the recipe reduces the level of bacterial contamination of the finished product.

Thus, the addition of beet fiber to minced chopped semi-finished products in an amount of $50 \%$ of the bread content is optimal in terms of forming the consistency and taste of the product, contributes to its enrichment with dietary fibers and also allows you to preserve the quality.

\section{References}

1. N. O'Shea, E. K. Arendt, E. Gallagher, Dietary fiber and phytochemical characteristics of fruit and vegetable by-products and their recent applications as novel ingredients in food products, Innovative Food Science and Emerging Technologies 16 (2012) Doi: 10.1016/J.IFSET.2012.06.002 
2. M. Han, H. C. Bertram, Designing healthier comminuted meat products: Effect of dietary fiber on water distribution and texture of a fat-reduced meat model system. Meat Science 133, 159 (2017) Doi: 10.1016/j/meatsci.2017.07.001

3. M.G. Magomedov, L.A. Lobosova, A.A. Derkanosova The production of concentrated sugar beet juice and perspectives of its use. Proceedings of the Voronezh State University of Engineering Technologies.159 (2014)

4. K. Arun Das, Pramod Kumar Nanda, Pratap Madane, Subhasish Biswas, Jose M. Lorenzo A comprehensive review on antioxidant dietary fibre enriched meat-based functional foods, Trends in Food Science \& Technology, 99, 324, (2020) Doi: 10.1016/j.tifs.2020.03.010

5. F. Jiménez-Colmenero, G. Delgado-Pando Fibre-enriched meat products, Fibre-Rich and Wholegrain Foods. 329-330 (2013) Doi: 10.1533/9780857095787.4.329

6. A. Eric Decker, Yeonhwa Park Healthier meat products as functional foods. Meat Science. 86, 49-50 (2010) Doi: 10.1016/j.meatsci.2010.04.021

7. M. Juliana Conte-Junior Washed cashew apple fiber (Anacardium occidentale L.) as fat replacer in chicken patties._LWT - Food Science and Technology ${ }_{2}$ 71. 269 (2016) Doi: 10.1016/J.LWT.2016.04.005

8. L. T. Carvalho, M. A. Pires, J. C. Baldin, P. E. Sichetti, Partial replacement of meat and fat with hydrated wheat fiber in beef burgers decreases caloric value without reducing the feeling of satiety after consumption. Meat Science, 147. 53-55 (2019) Doi: 10.1016/j.meatsci.2018.08.010

9. M. Ellech, D. Bedidjan, O. Ruaso, S. Besbes, S. Blecker, H. Attia Dietary fiber and fiber-rich by-products of the food processing: Characterisation, technological functionality and commercial applications: a review. Food Chemistry, 124, 412 (2011). Doi: 10.1016/J.FOODCHEM.2010.06.077

10. F. Gutöhrlein, R. Morales-Medina, A.-L. Boje, S. Drusch, S. Schalow Modulating the hydration properties of pea hull fibre by its composition as affected by mechanical processing and various extraction procedures, Food Hydrocolloids, 107. (2020) Doi: 10.1016/j.foodhyd.2020.105958

11. U. Kehlet, M. Pagter, M. D. Aaslyng, A.Raben Meatballs with 3\% and 6\% dietary fibre from rye bran or pea fibre - Effects on sensory quality and subjective appetite sensations. 125.66-75 (2017) Doi: 10.1016/j.meatsci.2016.11.007

12. Z. Pietrasik, J.A.M. Janz Ultization of pea flour, starch-rich and fiber-rich fractions in low fat bologna. Food Research International, 43, Issue 2, 602-608 (2010) doi: 10.1016/j.foodres.2009.07.017

13. Z. Pietrasik, M. Sigvaldson, O.P. Soladoye, N.J. Gaudette Utilization of pea starch and fibre fractions for replacement of wheat crumb in beef burgers. Meat Science, 161. (2019) Doi: 10.1016/j.meatsci.2019.107974

14. L.T. Carvalho, M.A. Pires, J.C. Baldin, P.E.S. Munekata, Partial replacement of meat and fat with hydrated wheat fiber in beef burgers decreases caloric value without reducing the feeling of satiety after consumption. Meat Science. 147, 53-59 (2019) Doi: 10.1016/j.meatsci.2018.08.010

15. Nobuaki Sato, Yohei Takano, Masahiro Mizuno, Kouichi Nozaki, Shingo Umemura, Tsunetomo Matsuzawa, Yoshihiko Amano, Satoshi Makishima Production of feruloylated arabino-oligosaccharides (FA-AOs) from beet fiber by hydrothermal 
treatment. The Journal of Supercritical Fluids, 79, 84-85 (2013) Doi: 10.1016/J.SUPFLU.2013.01.012

16. I. Janice Harland Authorised EU health claim for sugar beet fibre. Foods, Nutrients and Food Ingredients with Authorised EU Health Claims. 113-120 (2018) Doi: 10.1016/b978-0-08-100922-2.00008-5

17. S.Fuller, L. C. Tapsell, E. J. Beck Creation of a fibre categories database to quantify different dietary fibres. Journal of Food Composition and Analysis, 71.37 (2018) Doi: 10.1016/J.JFCA.2018.05.004

18. S.P. Merenkova, O.V. Zinina, M. Stuart, E.K. Okuskhanova, N.V. Androsova Effects of dietary fiber on human: a review. Human. Sport. Medicine, 20, 1, 106 - 113(2020) Doi: $10.14529 / \mathrm{hsm} 200113$ 